Int. J. Electrochem. Sci., 14 (2019) $4288-4308$

\title{
Intergranular Corrosion of Silicon-Containing Duplex Stainless Steel Weldments
}

\author{
D. W. Kang ${ }^{1,2}$ and, H. W. Lee $e^{1, *}$ \\ ${ }^{1}$ Department of Materials Science and Engineering, Dong-A University, 840 Hadan-dong, Saha-gu, \\ Busan 49315, Republic of Korea \\ ${ }^{2}$ Korea Institute of Nuclear Safety, Daejeon 34142, Republic of Korea \\ *E-mail: hwlee@dau.ac.kr
}

doi: $10.20964 / 2019.05 .65$

Received: 12 July 2018 / Accepted: 1 October 2018 / Published: 10 April 2019

This study examined the effects of secondary phase and carbide formation, with varying Si content and aging time, on the intergranular corrosion of duplex stainless steel weldments. With longer aging time, accordingly greater formation of secondary phases and carbides was observed. A DL-EPR test was carried out to assess the resistance to intergranular corrosion, and from the results greater degrees of sensitization were associated with larger amounts of secondary phases and carbides. XPS depth profile results indicated the formation of $\mathrm{SiO}_{2}$ at the boundary between the $\mathrm{Cr}$ oxide layer and the metal layer had positive effects on the intergranular corrosion resistance.

Keywords: A. Stainless steel; B. IGC; C. Passive films;

\section{$\underline{\text { FULL TEXT }}$}

(C) 2019 The Authors. Published by ESG (www.electrochemsci.org). This article is an open access article distributed under the terms and conditions of the Creative Commons Attribution license (http://creativecommons.org/licenses/by/4.0/). 